\title{
A cylindrical Venn diagram model for categorical syllogisms Dan Constantin Radulescu
}

\begin{abstract}
One denotes $A(M, *)$ by $A_{1}$ and $A(*, M)$ by $A_{2}$, where * stands for either $S$ or $P$, and the same for the O categorical operator. This allows to dispense with the four syllogistic figures and reduces the number of the 24 classically valid syllogisms (CVS) to only 8 (not 15) distinct CVS plus 6 (not 9) distinct existential import (ei) CVS. Out of the 36 (not 64!) distinct pairs of categorical premises (PCP or just pairs), 19 pairs entail at least one logical conclusion and thus generate valid syllogistic arguments (in short, valid syllogisms or VS) split into two subsets: the CVS and the $V S \mid C V S$. The latter ones have $A(P, S), O(P, S)$ and $I\left(S^{\prime}, P^{\prime}\right)$ as conclusions, not the "(S,P)-type" conclusions required of the CVS. $\left(S^{\prime}, P^{\prime}, M^{\prime}\right.$ are the complementary sets of $S, P, M$ in a universal set $U$.) The other results are: (i) one can also dispense with most of the rules of valid syllogisms (such as "the middle term has to be distributed in at least one premise" and "two negative premises are not allowed"), (ii) any pair of categorical premises generates at least one VS unless 1. both premises are particular, or, 2. one premise is universal and one particular and they act one on $M$, the middle term, and the other premise acts on $M^{\prime}$ - its complement in $U$, (iii) the VS set is the (disjoint) union of three equivalence classes generated respectively by (a) two universal premises acting on both $M$ and $M^{\prime}$, (b) two universal premises both acting on either $M$ or $M^{\prime}$, (c) one universal premise and one particular premise both acting on either $M$ or $M^{\prime}$, (iv) inside each equivalence class, via a relabeling transformation of the sets $S, P, M, S^{\prime}, P^{\prime}, M^{\prime}$, any of the VS can be recast (or reformulated) as any other VS from the same class. This "naming invariance" suggests that, from a set theoretical point of view, the $(S, P)$ conclusion restriction is not meaningful. The VS $\mid C V S$ subset contains 6 VS and 7 ei VS.
\end{abstract}

Keywords: categorical syllogisms • categorical premises $\bullet$ cylindrical Venn diagram

- Karnaugh map

\section{The Cylindrical Venn diagram (the Karnaugh map for $n=3$ )}

\begin{tabular}{|r|r|r|r|}
\hline S'P'M & SP'M & SPM & S'PM \\
\hline S'P'M' & SP'M' & SPM' & S'PM' \\
\hline
\end{tabular}

Fig. 1

For easier drawing, the universal set $\mathrm{U}$ is graphed as a rectangle - but please imagine that the left and right borders of the rectangle are glued together, so that S'PM and S'P'M are adjacent, and S'PM' and S'P'M' are adjacent, too - as in the usual 3-circle Venn diagram. On this "cylindrical Venn diagram" - or Karnaugh map with $\mathrm{n}=3$, no inference rules and no axioms are needed to prove any of the syllogistic conclusions: it is self-evident that the 36 distinct pairs of categorical premises (PCP or just pairs) split into 5 classes - 2 classes do not entail any logical conclusions (LC), but 3 classes do, and thus generate valid syllogisms VS. Since the 8 subsets of Figure 1 are the "special/elementary" subsets one refers to all the time, one calls them just subsets; no other set will be a "subset". Note that is not necessary to replace Venn's circles (John Venn 1880) by squares (Alan Marquand 1881), to arrive at the the above conclusions via diagrams, but it is surely much easier to see the LC entailed by the PCP on a cylindrical Venn diagram/Karnaugh map for $\mathrm{n}=3$, than on a 3-circle Venn diagram. 


\section{Notations}

As known, $\mathrm{A}(\mathrm{M}, \mathrm{P})$ means “All $\mathrm{M}$ is $\mathrm{P}$ ”, i.e., the set $\mathrm{P}^{\prime} \mathrm{M}:=\mathrm{P}^{\prime} \cap \mathrm{M}$ is empty. Thus $\mathrm{A}(\mathrm{M}, \mathrm{P})$ acts on the $\mathrm{M}$ row, by emptying (two "horizontally adjacent" subsets) $\mathrm{P}^{\prime} \mathrm{M}=\mathrm{SP} \mathrm{M}+\mathrm{S}^{\prime} \mathrm{P}$ M. Compare the above to A(P,M), which means "All $\mathrm{P}$ is $\mathrm{M}^{\prime}$, i.e., the set $\mathrm{PM}=\mathrm{P} \cap \mathrm{M}^{\prime}=\varnothing$. Thus $\mathrm{A}(\mathrm{P}, \mathrm{M})$ acts on the $\mathrm{M}^{\prime}$ row, by emptying, two other horizontally adjacent subsets: $\mathrm{PM}^{\prime}=\mathrm{SPM}^{\prime}+\mathrm{S}^{\prime} \mathrm{PM}$ '. It follows that A(M,P) and A(P,M) empty subsets not only on different rows, but also on totally different/complementary columns.

We follow three conventions concerning the pairs of categorical $\{\mathrm{P}, \mathrm{S}\}$ premises:

1. Always list a PCP with the P-premise first, and the S-premise second. (P won't necessarily be the "predicate of the conclusion"; it's "just a set called P".)

2. Since $\mathrm{A}(\mathrm{M}, \mathrm{P}) \neq \mathrm{A}(\mathrm{P}, \mathrm{M})$, and $\mathrm{O}(\mathrm{M}, \mathrm{P}) \neq \mathrm{O}(\mathrm{P}, \mathrm{M})$, the operators $\mathrm{A}$ and $\mathrm{O}$ will receive an index: 1 or 2 , depending on the position of $\mathrm{M}$ inside the ordered pair on which they act.

3. Namely, define $\left.A_{1} o{ }^{*}, M\right\}:=A\left(M,{ }^{*}\right)$, and $A_{2} o\left\{{ }^{*}, M\right\}:=A(*, M)$, where ${ }^{*}$ is either $S$, or P. This way, when $A_{1}$, (resp. $A_{2}$ ), is applied to an unordered pair $\{*, M\}$, it will pick up $M$ as the first, (resp. second), set for $\mathrm{A}$ to act upon. One can now use a one letter indexed categorical operators to symbolize an $\mathrm{S}$ or $\mathrm{P}$ premise: the meaning of $\mathrm{A}_{1} \mathrm{~A}_{2}$ will be, (using the convention to firstly list the P-premise), $\mathrm{A}(\mathrm{M}, \mathrm{P}) \mathrm{A}(\mathrm{S}, \mathrm{M})$ - the premises of the syllogism Barbara. Same notation rule will be applied to the O operator. O(M,P) means "Some $\mathrm{M}$ is not $\mathrm{P}$ ", i.e., the set $\mathrm{P}^{\prime} \mathrm{M} \neq \varnothing$, and $\mathrm{O}(\mathrm{S}, \mathrm{M})$ will mean "Some $\mathrm{S}$ is not $\mathrm{M}$ ", i.e., the set $\mathrm{SM}^{\prime} \neq \varnothing$. Analogously, $\mathrm{O}_{1} \mathrm{o}\left\{{ }^{*}, \mathrm{M}\right\}:=\mathrm{O}\left(\mathrm{M},{ }^{*}\right)$, and $\mathrm{O}_{2} \mathrm{o}\left\{{ }^{*}, \mathrm{M}\right\}:=\mathrm{O}\left({ }^{*}, \mathrm{M}\right)$. The $\mathrm{E}$ and $\mathrm{I}$ operators do not need indices since they are symmetric. $\mathrm{E}(\mathrm{S}, \mathrm{M})$ means $\mathrm{SM}=\varnothing$ and $\mathrm{I}(\mathrm{S}, \mathrm{M})$ means $\mathrm{SM} \neq \varnothing$; they act on the $\mathrm{M}$ row, as $\mathrm{A}_{1}, \mathrm{O}_{1}$ do. Thus, a no index, or an index 1 operator, acts on the $\mathrm{M}$ row.

The only operators acting on the $\mathrm{M}^{\prime}$ row are $\mathrm{A}_{2}, \mathrm{O}_{2}$. Their respective actions on the $\mathrm{M}^{\prime}$ row are similar to the actions of $E$, resp. I, on the $M$ row: for example, $A(P, M)$ empties PM', E(P,M) empties PM, etc. Note that giving indices to $\mathrm{A}$ and $\mathrm{O}$ replaces the use of the 4 Figures into which the two premises' terms can be arranged. Keeping up with the "4 figures", resulted, e.g., in a quadruple naming - Ferio, Festino, Ferison, Fresison, denote one and the same syllogism: EI:O(S,P). Getting rid of the rest of "double naming”, (Celarent/Cesare, Celaront/Cesaro, Disamis/Dimaris, etc., etc.), reduces the number of valid syllogisms, (VS), from 24 to only 14 (with only 6 out of 14 - instead of 9 out of 24 - based on existential import (ei).

One more notation:

The "emptying operators" $\mathrm{A}_{1}, \mathrm{~A}_{2}$, and E appear in universal premises (All..., No...), and the "element laying” operators $\mathrm{O}_{1}, \mathrm{O}_{2}$, and I appear in particular (Some..., Some... not) premises. We'll order all six possible P-premises, (resp. all six possible S-premises), as vector components: $\mathbb{P}_{\mathrm{i}}=\left\{\mathrm{A}_{1}, \mathrm{E}, \mathrm{A}_{2}, \mathrm{O}_{1}, \mathrm{I}, \mathrm{O}_{2}\right\}$ o $\{\mathrm{P}, \mathrm{M}\}$, resp. $\mathbb{S}_{\mathrm{i}}$ $=\left\{\mathrm{A}_{1}, \mathrm{E}, \mathrm{A}_{2}, \mathrm{O}_{1}, \mathrm{I}, \mathrm{O}_{2}\right\} \mathrm{o}\{\mathrm{S}, \mathrm{M}\}$. All the possible PCP are the components of the direct product of these two vectors $L_{i j}=\mathbb{P}_{i} \otimes \mathbb{S}_{j}, i, j=1, . ., 6$. So, the total number of distinct pairs of premises is 36 . As it will be noticed below, 17 pairs do not entail any LC(s), 15 do each entail exactly one LC, and each of the 4 pairs of "2-row action" universal premises, entail 3 independent LC each, for a total number of 19 pairs of premises that entail a total of 27 LC. Thus, according to our definitions, starting with categorical pairs of premises in the S,P,M variables, (i.e., A,O,E,I applied to the terms/sets S,P,M), one obtains 27 valid syllogisms, (VS), out of which, 14 the CVS - have familiar names (even more than one familiar name per each CVS). Counting each set of two and the one set of four equivalent CVS as just one distinct syllogism per set, aka disregarding figures for equivalent, (or identical content), syllogisms, one gets just 8 CVS without ei, and 6 ei CVS.

\section{Examples of VS recasting for Darapti's class}

This class contains only five VS, (based 4 on ei on M, and one on ei on M'), out of which two are ei CVS:

1. $\mathrm{A}_{1} \mathrm{~A}_{1}=\mathrm{E}\left(\mathrm{M}, \mathrm{P}^{\prime}\right) \mathrm{E}\left(\mathrm{M}, \mathrm{S}^{\prime}\right): \mathrm{A}(\mathrm{M}, \mathrm{SPM}) \rightarrow \mathrm{I}(\mathrm{S}, \mathrm{P})(\mathrm{M} \neq \varnothing)$, Darapti, [All $\mathrm{M}$ is $\mathrm{P}, \mathrm{All} \mathrm{M}$ is $\mathrm{S} \rightarrow \mathrm{M}=\mathrm{SPM}$ ]

2. $\mathrm{EA}_{1}=\mathrm{E}(\mathrm{M}, \mathrm{P}) \mathrm{E}\left(\mathrm{M}, \mathrm{S}^{\prime}\right): \mathrm{A}\left(\mathrm{M}, \mathrm{SP}^{\prime} \mathrm{M}\right) \rightarrow \mathrm{O}(\mathrm{S}, \mathrm{P})(\mathrm{M} \neq \varnothing)$, Felapton/Fesapo, [No $\mathrm{M}$ is $\mathrm{P}, \mathrm{All} \mathrm{M}$ is $\left.\mathrm{S} \rightarrow \mathrm{M}=\mathrm{SP} \mathbf{M}^{\prime}\right]$ 
3. $\mathrm{EE}=\mathrm{E}(\mathrm{M}, \mathrm{P}) \mathrm{E}(\mathrm{M}, \mathrm{S}): \mathrm{A}\left(\mathrm{M}, \mathrm{S}^{\prime} \mathrm{P} M\right) \rightarrow \mathrm{I}\left(\mathrm{S}^{\prime}, \mathrm{P}^{\prime}\right)(\mathrm{M} \neq \varnothing)$,[No $\mathrm{M}$ is $\mathrm{P}$, No $\mathrm{M}$ is $\left.\mathrm{S} \rightarrow \mathrm{M}=\mathrm{S}^{\prime} \mathrm{P}^{\prime} \mathrm{M}\right]$

4. $\mathrm{A}_{2} \mathrm{~A}_{2}=\mathrm{E}\left(\mathrm{M}^{\prime}, \mathrm{P}\right) \mathrm{E}\left(\mathrm{M}^{\prime}, \mathrm{S}\right): \mathrm{A}\left(\mathrm{M}^{\prime}, \mathrm{S}^{\prime} \mathrm{P}^{\prime} \mathrm{M}^{\prime}\right) \rightarrow \mathrm{I}\left(\mathrm{S}^{\prime}, \mathrm{P}^{\prime}\right)\left(\mathrm{M}^{\prime} \neq \varnothing\right), \quad\left[\mathrm{All} \mathrm{P}\right.$ is $\mathrm{M}$, All $\mathrm{S}$ is $\left.\mathrm{M} \rightarrow \mathrm{M}^{\prime}=\mathrm{S}^{\prime} \mathrm{P}^{\prime} \mathrm{M}^{\prime}\right]$

5. $A_{1} E=E\left(M, P^{\prime}\right) E(M, S): A\left(M, S^{\prime} P M\right) \rightarrow O(P, S)(M \neq \varnothing), \quad\left[A l l M\right.$ is $P$, No $M$ is $\left.S \rightarrow M=S^{\prime} P M\right]$

The pair $\mathrm{A}_{1} \mathrm{~A}_{1}$ and its ei conclusion $\mathrm{I}(\mathrm{S}, \mathrm{P})$ can be recast as any of the other four pairs and their respective ei conclusions via these relabelings of the $\mathrm{S}, \mathrm{P}, \mathrm{M}, \mathrm{S}^{\prime}, \mathrm{P}^{\prime}, \mathrm{M}^{\prime}$ sets:

$$
1 \leftrightarrow 2: \mathrm{P}^{\prime} \leftrightarrow \mathrm{P} ; 1 \leftrightarrow 3: \mathrm{S}^{\prime} \leftrightarrow \mathrm{S}, \mathrm{P}^{\prime} \leftrightarrow \mathrm{P} ; 1 \leftrightarrow 4: \mathrm{M}^{\prime} \mathrm{M}^{\prime}, \mathrm{S}^{\prime} \leftrightarrow \mathrm{S}, \mathrm{P}^{\prime} \leftrightarrow \mathrm{P} ; 1 \leftrightarrow 5: \mathrm{S}^{\prime} \leftrightarrow \mathrm{S}
$$

For example, in "set language" $A_{1} A_{1}$ means that $M$ is contained in the SP intersection; $A_{2} A_{2}$ means that $S$ and $P$ are included in $\mathrm{M}$, while their relative position inside $\mathrm{M}$ is undetermined. But this also means that $\mathrm{S}^{\prime}$ and $\mathrm{P}^{\prime}$ both include $\mathrm{M}^{\prime}$, which turns $\mathrm{A}_{2} \mathrm{~A}_{2}$ into an " $\mathrm{A}_{1} \mathrm{~A}_{1}$ situation" - only now we have to use the $\mathrm{S}^{\prime}, \mathrm{P}^{\prime}, \mathrm{M}^{\prime}$ ' variables in the "new" $A_{1} A_{1}$ : All $M^{\prime}$ is $P^{\prime}, A l l M^{\prime}$ is $S^{\prime}$, with the Darapti like conclusion: $I\left(S^{\prime}, P^{\prime}\right)$ if $M^{\prime} \neq \varnothing$, which would have been the entailed conclusion of $A_{2} A_{2}$ all along, without any recasting as $A_{1} A_{1}$. In "set language" $E A_{1}$ means that $M$ and $\mathrm{P}$ are disjoint and $\mathrm{M}$ is included in $\mathrm{S}$. The relative position of $\mathrm{S}$ and $\mathrm{P}$ is unknown. But the relative position of $\mathrm{S}, \mathrm{P}^{\prime}$ and $M$ is perfectly known: $M$ is contained in the $S P^{\prime}$ intersection. We have again an " $A_{1} A_{1}$ situation" in the $S, P^{\prime}, M$ variables: All M is $\mathrm{P}^{\prime}$, All $\mathrm{M}$ is $\mathrm{S}$, with its modified Darapti conclusion $\mathrm{I}\left(\mathrm{S}, \mathrm{P}^{\prime}\right)=\mathrm{O}(\mathrm{S}, \mathrm{P})$ if $\mathrm{M} \neq \varnothing$; which would have been the Felapton/Fesapo conclusion anyhow, without any $\mathrm{A}_{1} \mathrm{~A}_{1}$ recasting of $\mathrm{EA}_{1}$. The above shows that all five ei VS in this class should be indeed considered valid syllogisms and that there is no logical motivation for the $(\mathrm{S}, \mathrm{P})$ conclusion restriction, neither for most "rules of valid syllogisms" - $\mathrm{M}$ is undistributed in both $\mathrm{A}_{2} \mathrm{~A}_{2}$ premises, and $\mathrm{EE}$ are two negative premises that entail the $\mathrm{I}\left(\mathrm{S}^{\prime}, \mathrm{P}^{\prime}\right)$ ei conclusion when $\mathrm{M} \neq \varnothing$, with or without any recasting into the "CVS approved" pairs $\mathrm{A}_{1} \mathrm{~A}_{1}$, or $\mathrm{EA}_{1}$. For more details about equivalences between valid syllogisms please see Section 6 below.

\section{Conclusions' shape}

As one can see from the below discussion of all the possible pairs of premises, each and every one of the entailed LC refers precisely to one subset (out of 8), and falls in one of the following two categories:

$(\boldsymbol{\alpha})$ one, or even two, of the sets $\mathrm{S}, \mathrm{P}, \mathrm{M}, \mathrm{S}^{\prime}, \mathrm{P}^{\prime}, \mathrm{M}^{\prime}$ is reduced, via two universal, (aka emptying), premises to only one of its 4 subsets

( $\beta$ ) one of the 8 subsets in Figure 1 is shown to be $\neq \varnothing$ (possibly via an existential import (ei) supposition).

When ei is used, the conclusion is reached in two stages: first one of $\mathrm{S}, \mathrm{P}, \mathrm{M}, \mathrm{S}^{\prime}, \mathrm{P}^{\prime}$, or $\mathrm{M}^{\prime}$ is reduced to just one subset out of 4 (stage $(\boldsymbol{\alpha})$ ), then, the ei makes/declares that subset $\neq \varnothing$.

The above ( $\boldsymbol{\alpha})$ and $(\boldsymbol{\beta})$ express the fact that a PCP entailing an LC pinpoints to just one subset out of 8 . Note that there is a "tension" between the "one subset out of 8 conclusion" to which a PCP pinpoints, and the "Aristotle's requirement" that the conclusion of a valid syllogism, LC, should not contain the middle term. The latter condition means that the LC refers to a column containing two subsets - one included in $\mathrm{M}$, the other in $\mathrm{M}^{\prime}$. The difference in information between a PCP that pinpoints to just one subset out of 8 and the standard expression for an $\mathrm{LC}$ which refers to a column and thus pinpoints to two subsets out of 8 , is a consequence of the requirement that the middle term should not appear in the conclusion. One can say that the LC summarizes the "new knowledge" obtained from the pair of premises, and that to list the LC together with all the other information the premises provide would necessarily mean to relist one or both premises together with the LC - and this is exactly what we do not want to do, as per "Aristotle's requirement" (Striker 2009: 20): "A syllogism is an argument in which, certain things being posited, something other than what was laid down results by necessity because these things are so." One way to keep all the information a PCP provides, without completely relisting the premises would be to spell out the LC together with the subset the LC is "bound" to. For example, since a CVS requires an "(S,P) conclusion", i.e., that, in the conclusion, one of the operators A,O,E,I be applied to the ordered pair (S, P), all CVS conclusions are in fact necessarily bound to SPM, or SP'M, or SP'M'! (One can check below, Section 5, that there is no PCP pinpointing to the SPM' subset.) Any VS, bound to any other subset, has no name. (But, for 
example, LCs "bound to SPM" are A(S,P) (Barbara), I(S,P) (Barbari, Bramantip, Darapti, Darii/Datisi, Disamis/Dimaris), $A(P, S)$. The last one, originates from the VS $A_{2} A_{1}: P=S P M, S^{\prime}=S^{\prime} P^{\prime} M{ }^{\prime}$. Then one gets $A(P$, SPM), and thus $A(P, S)$, which has no name, even if the conclusion is bound to SPM, because $A_{2} A_{1}$ empty the set $P$ except for SPM, and this does not fit the CVS requirement for an "(S,P) conclusion". But the ei, $(\mathrm{P} \neq \varnothing)$, conclusion, I(S,P), gives the CVS Bramantip.

When one premise is universal and the other one is particular, then the LC, entailed if and only if both premises act on the same set - either M or 'M' but not both, is reached in one stage: one of the 8 subsets in Figure 1 , uniquely determined, turns out to be $\neq \varnothing$. (The particular premise will have available only one subset, not two, to lay an element on, since the other horizontally adjacent subset was "just" emptied by the universal premise: only this arrangement can make both premises TRUE and the syllogistic argument valid. See Fact \#1 below.) A standard LC will still refer to an entire column and not just one subset.

Note that any subset relabeling, such as, for example, $\mathrm{P}^{\prime} \leftrightarrow \mathrm{M}, \mathrm{S} \leftrightarrow \mathrm{S}^{\prime}$, does not change the immediate neighbours of any of the subsets, and does not change the conclusions of any of the premises' pairs: the conclusion of "All $P$ is $M$, All M is $S$ " $=A_{2} A_{1}$, on a new, "relabeled Figure 1", will still be $P=S P M, S^{\prime}=S^{\prime} P^{\prime} M{ }^{\prime}$.

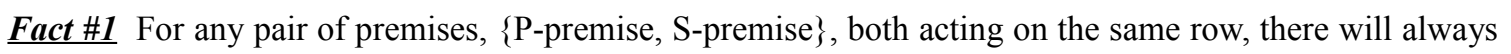
be one and only one subset "acted upon twice"; for any pair \{P-premise, S-premise\}, acting on two rows, there will always be one and only one column whose two subsets are both acted upon.

Proof: Cf. Fig. 1, two of the sets S, P, S', P', unless they are complementary sets, always have one and only one common column. Consider first the "M-row operators" $A_{1}, O_{1}, E$, I. In a P-premise, the operators $A_{1}, O_{1}$ act on the two $\mathrm{P}^{\prime}$ columns and the E,I operators act on the two P columns. In an S-premise, the operators $\mathrm{A}_{1}, \mathrm{O}_{1}$ act on the two $\mathrm{S}^{\prime}$ columns and the E,I operators act on the two $\mathrm{S}$ columns. Thus a pair (P-premise, S-premise), both acting on the $\mathrm{M}$ row, may act either on $\left\{\mathrm{P}^{\prime}, \mathrm{S}^{\prime}\right\}$, or on $\left\{\mathrm{P}^{\prime}, \mathrm{S}\right\}$, or on $\left\{\mathrm{P}, \mathrm{S}^{\prime}\right\}$, or on $\{\mathrm{P}, \mathrm{S}\}$, in which cases, respectively, either the subset $\mathrm{S}^{\prime} \mathrm{P}^{\prime} \mathrm{M}$, or $\mathrm{SP}^{\prime} \mathrm{M}$, or $\mathrm{S}^{\prime} \mathrm{PM}$, or SPM is acted upon twice, and, respectively, either the subset SPM, or S'PM, or SP'M, or S'P'M is not acted upon at all. Thus two universal premises acting on the same row will empty 3 subsets, (of $\mathrm{M}$ or $\mathrm{M}^{\prime}$ ), and one universal and one particular premise acting on the same row will always place a set element on precisely one subset.

Since the $\mathrm{A}_{2}, \mathrm{O}_{2}$ operators - which act on the $\mathrm{M}^{\prime}$ row - behave similarly to the E,I operators which act on $\mathrm{M}$ row - i.e., in a P-premise, the operators $\mathrm{A}_{2}, \mathrm{O}_{2}$ act on the two P columns, (exactly as E,I do on the M row), and in an S-premise, the operators $\mathrm{A}_{2}, \mathrm{O}_{2}$ act on the two $\mathrm{S}$ columns, (exactly as E,I do on the M row), it follows, as above, that a "2-row acting" pair of premises will always "act upon a column twice" either emptying both column's subsets, (and this is the only interesting case!), or possibly laying set elements in both column's subsets, or emptying one of the column's subset and laying a set element on the other column's subset - all these latter variants correspond to pairs of premises that do not entail any LC. (See below the paragraphs (i) and (ii2).) The four 2-row acting pairs of universal premises will thus empty one column, plus two other subsets, located on two different rows, on each side of that emptied column.(See the paragraph (iil) below.) QED. (An examination of the 36 cases below makes the proof of Fact \#1 clear, too.)

\section{A more detailed discussion of the matrix $L_{i j}, i, j=1, . ., 6$}

The matrix $L_{i j}=\mathbb{P}_{i} \otimes \mathbb{S}_{j}, i, j=1,6$ naturally splits into four 3 by 3 sub matrices: $L^{(1)}:=L_{i j}, i, j=1,2,3$, contains only, (and they are the only ones), pairs of two universal premises; $L^{(2)}:=L_{i j}, i=4,5,6, j=1,2,3$, contains pairs of one particular P-premise, [gotten from replacing in $\mathrm{L}^{(1)}$ the universal P-premise with the corresponding, (and contradictory), particular P-premise], and one universal S-premise (left unchanged from $\left.\mathrm{L}^{(1)}\right) ; \mathrm{L}^{(3)}:=\mathrm{L}_{\mathrm{ij}}$, $\mathrm{i}=1,2,3, \mathrm{j}=4,5,6$, contains pairs of one universal P-premise, (unmodified from $\mathrm{L}^{(1)}$ ), and one particular S-premise, [gotten from replacing in $\mathrm{L}^{(1)}$ the universal S-premise with the corresponding, (and contradictory), particular S- 
premise]; and the sub-matrix $\mathrm{L}^{(4)}:=\mathrm{L}_{\mathrm{ij}}, \mathrm{i}, \mathrm{j}=4,5,6$ which contains only, (and they are the only ones), pairs of two particular premises.

(i) $\mathbf{L}^{(4)}$ : The pairs of premises in the sub-matrix $L^{(4)}:=L_{i j}, i, j=4,5,6$, do not entail any $L C$. The two particular premises will "lay set elements" either on three subsets of the same row ( $\mathrm{M}$ or $M^{\prime}$ ), or on 4 subsets on different rows. Since, any conclusion of such a pair would just relist one or two of its premises, there is no way to satisfy Aristotle's requirement, (Striker 2009: 20), that "A syllogism is an argument in which, certain things being posited, something other than what was laid down results by necessity because these things are so." Thus, per Aristotle's insight, these pairs will not generate any valid syllogism, VS; this means nine pairs of premises on the no conclusion/discarded list.

(ii) $\mathbf{L}^{(1)}$ : contains two sorts of universal premises pairs:

(ii0) The 5 "1-row acting" pairs of universal premises. Four pairs act on the $M$ row only, $L_{11}=A_{1} A_{1}, L_{12}$ $=A_{1} E, L_{21}=E A_{1}, L_{22}=E E$, and, one pair acts on the $M^{\prime}$ row only, $L_{33}=A_{2} A_{2}$. As the Fact \#1 has shown, the $M$ subsets SPM, or S'PM, or SP'M, or S'P'M are not emptied by $\mathrm{L}_{11}=\mathrm{A}_{1} \mathrm{~A}_{1}, \mathrm{~L}_{12}=\mathrm{A}_{1} \mathrm{E}, \mathrm{L}_{21}=\mathrm{EA}_{1}, \mathrm{~L}_{22}=\mathrm{EE}$, respectively, and the S'P'M' subset of $\mathrm{M}^{\prime}$ is not emptied by $\mathrm{L}_{33}=\mathrm{A}_{2} \mathrm{~A}_{2}$. Again, as per Aristotle's insight, only existential imports on M, resp., M', will count and produce $5 \mathrm{VS}$, each respectively "bound" on one of the above not emptied subsets. ( 2 out of 5 are the CVS Darapti and Felapton/Fesapo, bound on SPM and SP'M, respectively.) Thus the 5 "1-row acting" pairs of universal premises each produces one ei conclusion or VS, since we get one conclusion if ei is used each time one of the sets M, or M', is reduced, via two "1-row acting" universal premises, to only one of its 4 subsets.

(ii1) The 4 "2-row acting" pairs of universal premises. They have to contain $\mathrm{A}_{2}$ as a premise - since this is the only universal operator acting on the $2^{\text {nd }}$ row $\mathrm{M}^{\prime}$. These 4 pairs are: $\mathrm{L}_{13}=\mathrm{A}_{1} \mathrm{~A}_{2}, \mathrm{~L}_{23}=\mathrm{EA}_{2}, \mathrm{~L}_{31}=\mathrm{A}_{2} \mathrm{~A}_{1}$, $\mathrm{L}_{32}=\mathrm{A}_{2} \mathrm{E}$. They empty four subsets on two different rows and three different columns, located, cf. Fact $\# 1$, as follows: two empty subsets are on the same column, and the other two empty subsets are on different rows and on different sides of the empty column. These pairs are responsible for 12 different conclusions:

1. The pair of premises $L_{13}=A_{1} A_{2}=A(M, P) A(S, M)=E\left(M, P^{\prime}\right) E\left(M^{\prime}, S\right)$ empties the column $S^{\prime}$ and the subsets $\mathrm{S}^{\prime} \mathrm{P}^{\prime} \mathrm{M}$ and SPM', and, out of the 3 columns SP', S'P' and SP, occupied by the sets $\mathrm{S}$ and $\mathrm{P}^{\prime}$, (whose intersection is $\mathrm{SP}^{\prime}$ ), only the subsets SPM out of $\mathrm{S}$, and $\mathrm{S}^{\prime} \mathrm{P}^{\prime} \mathrm{M}^{\prime}$ out of $\mathrm{P}^{\prime}$ " "survive". LCs are therefore aplenty: $\mathrm{A}(\mathrm{S}, \mathrm{SPM}), \mathrm{A}\left(\mathrm{P}^{\prime}, \mathrm{S}^{\prime} \mathrm{P}^{\prime} \mathrm{M}^{\prime}\right), \mathrm{E}\left(\mathrm{S}, \mathrm{P}^{\prime}\right)$, from which it follows $\mathrm{A}(\mathrm{S}, \mathrm{P}), \mathrm{A}\left(\mathrm{P}^{\prime}, \mathrm{S}^{\prime}\right), \mathrm{E}\left(\mathrm{S}, \mathrm{P}^{\prime}\right), \mathrm{A}(\mathrm{S}, \mathrm{M}), \mathrm{A}\left(\mathrm{P}^{\prime}, \mathrm{M}^{\prime}\right)$. But the last two conclusions are exactly the premises - so they do not count, (as new knowledge), and the first three, via set theory, (or contraposition and obversion), are equivalent: $\mathrm{A}(\mathrm{S}, \mathrm{P})=\mathrm{A}\left(\mathrm{P}^{\prime}, \mathrm{S}^{\prime}\right)=\mathrm{E}\left(\mathrm{S}, \mathrm{P}^{\prime}\right)$. We'll keep just $\mathrm{A}(\mathrm{S}, \mathrm{P})$ as the only one universal conclusion, out of the three independent conclusions entailed by the "Barbara pair of premises" $L_{13}=A_{1} A_{2}$. The other two independent conclusions involve ei: on $S$, i.e., supposing $S \neq \varnothing$, one gets $\mathrm{I}(\mathrm{S}, \mathrm{P})$, Barbari, and, via ei on $\mathrm{P}^{\prime}$, one gets the no name $\mathrm{I}\left(\mathrm{P}^{\prime}, \mathrm{S}^{\prime}\right)$, for a total of three independent conclusions entailed by the pair $L_{13}=A_{1} A_{2}=A(M, P) A(S, M)$. Any other conclusions, such as $I(S, M)$ or $I(P, M)$ are not independent: they follow directly from the premises and $\mathrm{S} \neq \varnothing$. Moreover, $\mathrm{P}^{\prime}=\mathrm{S}^{\prime} \mathrm{P}^{\prime} \mathrm{M}^{\prime}$ follows from $\mathrm{S}=\mathrm{SPM}$ : if we list, (now, for simplicity, on one row), from left to right, the adjacent/neighbouring subsets that were not emptied by Barbara's premises, they are SPM, S'PM, S'PM', S'P'M'. This reads, from left to right, (resp. from right to left), precisely as $\mathrm{S} \subseteq \mathrm{M} \subseteq \mathrm{P}$, and, resp., $\mathrm{P}^{\prime} \subseteq \mathrm{M}^{\prime} \subseteq \mathrm{S}^{\prime}-$ which is also how the transitivity of the inclusions $\mathrm{A}(\mathrm{S}, \mathrm{M})$, $\mathrm{A}(\mathrm{M}, \mathrm{P})$, or the Euler diagrams, would have represented Barbara's premises.

2. Analogously, the premises $A_{2} A_{1}=A(P, M) A(M, S)=E\left(M^{\prime}, P\right) E\left(M, S^{\prime}\right)$, empty 4 subsets out of 6 from the columns $\mathrm{S}^{\prime} \mathrm{P}, \mathrm{S}^{\prime} \mathrm{P}^{\prime}$ and $\mathrm{SP}$, occupied by the sets $\mathrm{S}^{\prime}$ and $\mathrm{P}$, (whose intersection is $\mathrm{S}^{\prime} \mathrm{P}$ ). Only the subsets SPM out of P and $\mathrm{S}^{\prime} \mathrm{P}^{\prime} \mathrm{M}$ ' out of $\mathrm{S}^{\prime}$ will again "survive". Thus, same "survivors" but now as parts of other "big sets" $\mathrm{S}$ ', $\mathrm{P}$ instead of $\mathrm{S}, \mathrm{P}$ '. The independent conclusions are the no name $\mathrm{A}(\mathrm{P}, \mathrm{S})$, and, via ei on $\mathrm{P}$, $\mathrm{I}(\mathrm{S}, \mathrm{P})$ - Bramantip. Via ei on $\mathrm{S}^{\prime}$, one gets (again) a no name $\mathrm{I}\left(\mathrm{P}^{\prime}, \mathrm{S}^{\prime}\right)$. One can also see, that via a simple relabeling transformation, $\mathrm{M} \rightarrow \mathrm{M}, \quad \mathrm{S} \rightarrow \mathrm{P}, \quad \mathrm{P} \rightarrow \mathrm{S}, \quad \mathrm{A}_{2} \mathrm{~A}_{1} \quad$ becomes $\mathrm{A}_{1} \mathrm{~A}_{2}: \mathrm{A}_{2} \mathrm{~A}_{1}=\mathrm{A}(\mathrm{P}, \mathrm{M}) \mathrm{A}(\mathrm{M}, \mathrm{S}) \rightarrow$ $\mathrm{A}(\mathrm{S}, \mathrm{M}) \mathrm{A}(\mathrm{M}, \mathrm{P})=\mathrm{E}\left(\mathrm{M}, \mathrm{P}^{\prime}\right) \mathrm{E}\left(\mathrm{M}^{\prime}, \mathrm{S}\right)$. One can also see, that via another relabeling transformation, $\mathrm{M} \rightarrow \mathrm{M}^{\prime}$, $\mathrm{S} \rightarrow \mathrm{S}^{\prime}, \quad \mathrm{P} \rightarrow \mathrm{P}^{\prime}, \quad \mathrm{A}_{2} \mathrm{~A}_{1}$ also becomes $\mathrm{A}_{1} \mathrm{~A}_{2}: \mathrm{A}_{2} \mathrm{~A}_{1}=\mathrm{A}(\mathrm{P}, \mathrm{M}) \mathrm{A}(\mathrm{M}, \mathrm{S}) \rightarrow \mathrm{A}\left(\mathrm{P}^{\prime}, \mathrm{M}^{\prime}\right) \mathrm{A}\left(\mathrm{M}^{\prime}, \mathrm{S}^{\prime}\right)=\mathrm{E}\left(\mathrm{M}, \mathrm{P}^{\prime}\right) \mathrm{E}\left(\mathrm{M}^{\prime}, \mathrm{S}\right)$, [or one may use contraposition on $A\left(\mathrm{P}^{\prime}, \mathrm{M}^{\prime}\right)$ to get $\mathrm{A}(\mathrm{M}, \mathrm{P})$, and on $\mathrm{A}\left(\mathrm{M}^{\prime}, \mathrm{S}^{\prime}\right)$ to get $\left.\mathrm{A}(\mathrm{S}, \mathrm{M})\right]$. The 
difference between the two relabeling transformations is that the first one also maps the conclusions of $A_{2} A_{1}$ onto the conclusions of $A_{1} A_{2}$. [See next section for all the relabeling transformations between the VS generared by the 4 "2-row acting" pairs of universal premises.]

3. The $\mathrm{EA}_{2}=\mathrm{E}(\mathrm{M}, \mathrm{P}) \mathrm{E}\left(\mathrm{M}^{\prime}, \mathrm{S}\right)$ and $\mathrm{A}_{2} \mathrm{E}=\mathrm{E}\left(\mathrm{M}^{\prime}, \mathrm{P}\right) \mathrm{E}(\mathrm{M}, \mathrm{S})$ are even more similar than $\mathrm{A}_{1} \mathrm{~A}_{2}$ and $\mathrm{A}_{2} \mathrm{~A}_{1}$ are. Each of $\mathrm{EA}_{2}$ and $\mathrm{A}_{2} \mathrm{E}$, empty 4 subsets out of the 6 subsets of same 3 columns SP', SP' and SP. The two subsets that survive are: $\mathrm{SP}^{\prime} \mathrm{M}$ and $\mathrm{S}^{\prime} \mathrm{PM} \mathrm{M}^{\prime}$ if the premises are $\mathrm{EA}_{2}$, and $\mathrm{SP}^{\prime} \mathrm{M}^{\prime}$ and $\mathrm{S}^{\prime} \mathrm{PM}$ if the premises are $\mathrm{A}_{2} \mathrm{E}$. The type $(\alpha)$, two entailed LCs per pair of premises, are thus, for $\mathrm{EA}_{2}$ : $\mathrm{A}\left(\mathrm{S}, \mathrm{SP} \mathrm{P}^{\prime} \mathrm{M}\right), \mathrm{A}\left(\mathrm{P}, \mathrm{S}^{\prime} \mathrm{PM}^{\prime}\right)$. One chooses, as independent conclusions $\mathrm{E}(\mathrm{S}, \mathrm{P})\left(=\mathrm{A}\left(\mathrm{S}, \mathrm{P}^{\prime}\right)=\mathrm{A}\left(\mathrm{P}, \mathrm{S}^{\prime}\right)\right)$, (Celarent/Cesare), and, via ei on $\mathrm{P}$ the no name $\mathrm{O}(\mathrm{P}, \mathrm{S})$, plus, via ei on $\mathrm{S}, \mathrm{O}(\mathrm{S}, \mathrm{P})$, (Celaront/Cesaro).

4. Initial conclusions for $\mathrm{A}_{2} \mathrm{E}$ are: $\mathrm{A}\left(\mathrm{S}, \mathrm{SP}^{\prime} \mathrm{M}{ }^{\prime}\right), \mathrm{A}\left(\mathrm{P}, \mathrm{S}^{\prime} \mathrm{PM}\right)$. One chooses, as independent conclusion $\mathrm{E}(\mathrm{S}, \mathrm{P})$ $\left(=\mathrm{A}\left(\mathrm{S}, \mathrm{P}^{\prime}\right)=\mathrm{A}\left(\mathrm{P}, \mathrm{S}^{\prime}\right)\right),($ Camestres/Camenes $)$. And, via ei on $\mathrm{P}$, the no name $\mathrm{O}(\mathrm{P}, \mathrm{S})$, plus, via ei on $\mathrm{S}$, $\mathrm{O}(\mathrm{S}, \mathrm{P})$, (Camestrop/Camenop). This way, we get again to three independent conclusions when ei is used each time one of the sets $\mathrm{S}, \mathrm{P}, \mathrm{S}^{\prime}, \mathrm{P}^{\prime}$ is reduced, via two "2-row acting" universal premises, to only one of its 4 subsets.

(iii) $\mathbf{L}^{(2)}$ and $\mathbf{L}^{(3)}$. Firstly, observe that the "2-row acting", 1-particular, 1-universal pairs of premises from $\mathrm{L}^{(2)}$ : $\mathrm{L}_{43}=\mathrm{O}_{1} \mathrm{~A}_{2}, \mathrm{~L}_{53}=\mathrm{IA}_{2}, \mathrm{~L}_{61}=\mathrm{O}_{2} \mathrm{~A}_{1}, \mathrm{~L}_{62}=\mathrm{O}_{2} \mathrm{E}$, and from $\mathrm{L}^{(3)}$ : $\mathrm{L}_{16}=\mathrm{A}_{1} \mathrm{O}_{2}, \mathrm{~L}_{26}=\mathrm{EO}_{2}, \mathrm{~L}_{34}=\mathrm{A}_{2} \mathrm{O}_{1}$, $\mathrm{L}_{35}=\mathrm{A}_{2} \mathrm{I}$, do not entail any conclusion. These 8 pairs are gotten from the 4 (iil) pairs, by substituting a particular premise in place of an universal premise. But by doing this, the emptying, and the element laying, happen now on two different rows. Any LC would just relist the premises. Thus, as per Aristotle's insight, the 8 pairs of 1-particular, 1-universal premises, acting on 2 rows, $M$ and $M^{\prime}$, span the $2^{\text {nd }}$ class of pairs that do not entail any LC. This adds up to a total of $9+8=17$ of such pairs. Out of the other $36-17=19$ pairs, we already saw 4 pairs of premises, (ii1), that entail 3 independent conclusions per pair, and 5 pairs of premises, (ii0), that entail one conclusion per pair. The rest of 10 pairs from $\mathrm{L}^{(2)}$ and $\mathrm{L}^{(3)}$, originate from the 5 "1-row acting" pairs of universal premises in $\mathrm{L}^{(1)}$, by replacing one universal premise with its contradictory particular premise, and thus, cf. Fact \#1, each such pair results in one precise subset being $\neq \varnothing$, and entails exactly one LC per pair, for a total of 27 valid syllogisms, (VS), 14 out of which - the classically valid syllogisms, (CVS), have names [even multiple names for one and the same syllogism, (or pair of premises), when the premises' terms can be switched around without changing the premises' meaning]. More precisely, the five $\mathrm{L}^{(2)}$ pairs, (which were obtained from $\mathrm{L}^{(1)}$ 's five "1-row acting" universal pairs, by changing an universal P-premise into its contradictory, particular P-premise): $\mathrm{L}_{41}=\mathrm{O}_{1} \mathrm{~A}_{1}, \mathrm{~L}_{42}=\mathrm{O}_{1} \mathrm{E}, \mathrm{L}_{51}=\mathrm{IA}_{1}, \mathrm{~L}_{52}=\mathrm{IE}, \mathrm{L}_{63}=\mathrm{O}_{2} \mathrm{~A}_{2}$, lead to, in order, the following ( $\beta$ ) type, conclusions: $S P^{\prime} M \neq \varnothing$ (or $\mathrm{O}(\mathrm{S}, \mathrm{P})$, Bocardo), $\mathrm{S}^{\prime} \mathrm{P}^{\prime} \mathrm{M} \neq \varnothing$ (or I(S', $\left.\mathrm{P}^{\prime}\right)$, no name), $\mathrm{SPM} \neq \varnothing$ (or I(S,P), Disamis/Dimaris), $\mathrm{S} \mathrm{PM} \neq \varnothing$ (or $\mathrm{O}(\mathrm{P}, \mathrm{S})$ no name), $\mathrm{S}^{\prime} \mathrm{PM} \prime \varnothing \varnothing$ (or $\mathrm{O}(\mathrm{P}, \mathrm{S})$ no name). For the last 5 out of 10 , one substitutes the contradictory particular S-premise for the universal S-premise of the $\mathrm{L}^{(1)}$ 's five "1-row acting" universal pairs, to obtain: $\mathrm{L}_{14}=\mathrm{A}_{1} \mathrm{O}_{1}, \mathrm{~L}_{24}=\mathrm{EO}_{1}, \mathrm{~L}_{15}=\mathrm{A}_{1} \mathrm{I}, \mathrm{L}_{25}=\mathrm{EI}, \mathrm{L}_{36}=\mathrm{A}_{2} \mathrm{O}_{2}$. The conclusions of these pairs are,

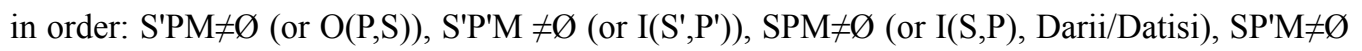
(or $\mathrm{O}(\mathrm{S}, \mathrm{P})$, Ferio/Festino/Ferison/Fresison), $\mathrm{SP}^{\prime} \mathrm{M}^{\prime} \neq \varnothing$ (or $\mathrm{O}(\mathrm{S}, \mathrm{P})$, Baroco). One can notice that $\mathrm{A}_{1} \mathrm{O}_{1}$ and IE have the same conclusion $\mathrm{S}^{\prime} \mathrm{PM} \neq \varnothing, \mathrm{O}_{1} \mathrm{~A}_{1}$ and EI have the same conclusion $\mathrm{SP}^{\prime} \mathrm{M} \neq \varnothing, \mathrm{IA}_{1}$ and $\mathrm{A}_{1} \mathrm{I}$ have the same conclusion $\mathrm{SPM} \neq \varnothing, \mathrm{O}_{1} \mathrm{E}$ and $\mathrm{EO}_{1}$ have the same conclusion $\mathrm{S}^{\prime} \mathrm{P}^{\prime} \mathrm{M} \neq \varnothing$ (since on the $\mathrm{M}$ row there are only 4 subsets and one has 8 pairs of premises which place/lay at least one set element in exactly one subset of $\mathrm{M}$ ).

\section{Classes of equivalent syllogistic arguments}

The premises' action is easier to follow if we uniformly express any premise as either an E or I operator, acting firstly on $M$, or M', as the case may be. Consider for example the pairs: $\mathrm{A}_{1} \mathrm{~A}_{1}, \mathrm{O}_{1} \mathrm{~A}_{1}, \mathrm{~A}_{1} \mathrm{O}_{1}$. Write: 


\section{$\mathrm{A}_{1} \mathrm{~A}_{1}=\mathrm{E}\left(\mathrm{M}, \mathrm{P}^{\prime}\right) \mathrm{E}\left(\mathrm{M}, \mathrm{S}^{\prime}\right)$}

$\mathrm{O}_{1} \mathrm{~A}_{1}=\mathrm{I}\left(\mathrm{M}, \mathrm{P}^{\prime}\right) \mathrm{E}\left(\mathrm{M}, \mathrm{S}^{\prime}\right)$

$\mathrm{A}_{1} \mathrm{O}_{1}=\mathrm{E}\left(\mathrm{M}, \mathrm{P}^{\prime}\right) \mathrm{I}\left(\mathrm{M}, \mathrm{S}^{\prime}\right)$. All three pairs use the same variables $\mathrm{M}, \mathrm{P}^{\prime}, \mathrm{S}^{\prime}$. This is because, as was observed in Fact \#1's proof, $\mathrm{A}_{1} \mathrm{~A}_{1}$ acts twice on S'P'M, not at all on SPM, (we'll say that Darapti is bound not on the subset on which the premises' pair acts twice, but on SPM on which it doesn't act at all, and thus allows the conclusion $\mathrm{M}=$ SPM, out of which, via ei, the Darapti's conclusion follows. Equally important is that $\mathrm{A}_{1} \mathrm{~A}_{1}$ acts once on SP'M, and once on S'PM, the subsets next to S'P'M on the "cylindrical Venn diagram", and these are exactly the subsets assured to be $\neq \varnothing$ by $\mathrm{O}_{1} \mathrm{~A}_{1}$, (Bocardo), and $\mathrm{A}_{1} \mathrm{O}_{1}$, respectively.

Let's now consider another similar group of 3 pairs of premises:

$$
\mathrm{EE}=\mathrm{E}(\mathrm{M}, \mathrm{P}) \mathrm{E}(\mathrm{M}, \mathrm{S})
$$

$\mathrm{IE}=\mathrm{I}(\mathrm{M}, \mathrm{P}) \mathrm{E}(\mathrm{M}, \mathrm{S})$

$\mathrm{EI}=\mathrm{E}(\mathrm{M}, \mathrm{P}) \mathrm{I}(\mathrm{M}, \mathrm{S})$. All three pairs use the same variables M,P,S. This is because, as was observed in Fact \#1's proof, EE acts twice on SPM, not at all on S'P'M, (we'll say that the no name EE:M=S'P'M is bound not on the subset on which the premises' pair acts twice, but on S'P'M on which the pair doesn't act at all, and thus allows the conclusion $\mathrm{M}=\mathrm{S}^{\prime} \mathrm{P}^{\prime} \mathrm{M}$, out of which, via ei, the no name $\mathrm{I}\left(\mathrm{S}^{\prime}, \mathrm{P}^{\prime}\right)$ conclusion follows. Equally important is that EE acts once on SP'M, and once on S'PM, and these are exactly the subsets assured to be $\neq \varnothing$ by EI, (Ferio/Festino/Ferison/Fresison), and IE, respectively.

Fact \#2: if we relabel $\mathrm{P}^{\prime} \rightarrow \mathrm{P}, \mathrm{S}^{\prime} \rightarrow \mathrm{S}$, then the first group of 3 pairs of premises is transformed in the $2^{\text {nd }}$ group of 3 pairs of premises, and, the 3 conclusions from the $1^{\text {st }}$ group of pairs, via this relabeling, become the 3 conclusions of the $2^{\text {nd }}$ group of pairs. This happens because the subsets on which $\mathrm{A}_{1} \mathrm{~A}_{1}$ acted twice, resp. not at all, are mapped into subsets on which EE acts twice, resp. not at all. The same is true about the subsets on which $\mathrm{A}_{1} \mathrm{~A}_{1}$ acted once - they are transformed into subsets on which EE acts once. This way not only pairs of premises are mapped onto pairs of premises, but their conclusions are mapped into respective conclusions, too. There are 5 different groups of 3 pairs of premises each, and 4 relabeling transformations that map the first set of 3 pairs of premises to the other 4 and back to the $1^{\text {st }}$ groups of 3 pairs of premises. One can argue that only one set of 3 pairs of premises is independent and the rest represent just what one would have gotten by a relabeling of the variables $\mathrm{S}, \mathrm{P}, \mathrm{M}$. The final conclusion is that the 5 pairs of two universal premises acting on the same row, $\mathrm{A}_{1} \mathrm{~A}_{1}, \mathrm{EE}, \mathrm{A}_{1} \mathrm{E}$, $\mathrm{EA}_{1}, \mathrm{~A}_{2} \mathrm{~A}_{2}$ are equivalent, and all the other 10 pairs of premises, one universal and one particular, are equivalent, too. This is so because the two strains of 5 VS each, which start with $\mathrm{O}_{1} \mathrm{~A}_{1}$ and $\mathrm{A}_{1} \mathrm{O}_{1}$, and continue with IE and resp. EI, etc. are in fact equivalent, too: one can see this, for the above mentioned pairs, via a relabeling $S \leftrightarrow P$. Thus we have 10 pairs that generate equivalent VS: $\mathrm{O}_{1} \mathrm{~A}_{1}$, IE, $\mathrm{O}_{1} \mathrm{E}, \mathrm{IA}_{1}, \mathrm{O}_{2} \mathrm{~A}_{2}, \mathrm{~A}_{1} \mathrm{O}_{1}, \mathrm{EI}, \mathrm{A}_{1} \mathrm{I}, \mathrm{EO}_{1}, \mathrm{~A}_{2} \mathrm{O}_{2}$. The set of 4 "2-row acting" pairs of universal premises can be transformed, by relabeling, among themselves, too. Thus we found 3 different types of pairs of premises, easily characterized as being: 4 pairs of 2 universal premises acting on two rows, $\mathrm{M}$ and $\mathrm{M}^{\prime}, 5$ pairs of 2 universal premises acting on one row, $\mathrm{M}$ or $\mathrm{M}^{\prime}, 10$ pairs of one universal and one particular premises, acting on one row, $\mathrm{M}$ or $\mathrm{M}^{\prime}$. Thus one has 3 types of pairs of categorical premises (PCP) which generate valid syllogisms (VS).

Below one lists the VS from two classes out of three, grouped by the subset they do not act upon, and to which we say that they are "bound" to. One VS class contain 5 ei VS and the other one contains 10 VS, for a total of 15 VS split in five groups of three VS each - according to the subset they are bound to. These five VS groups use, (or act upon), the complementary variables to the variables characterizing the subset these VS are bound to.

1. VS bound to the subset SPM:
$\mathrm{A}_{1} \mathrm{~A}_{1}=\mathrm{E}\left(\mathrm{M}, \mathrm{P}^{\prime}\right) \mathrm{E}\left(\mathrm{M}, \mathrm{S}^{\prime}\right)$
$\mathrm{M}=\mathrm{SPM}$. If $\mathrm{M} \neq \varnothing$ : I(S,P), Darapti
$\mathrm{O}_{1} \mathrm{~A}_{1}=\mathrm{I}\left(\mathrm{M}, \mathrm{P}^{\prime}\right) \mathrm{E}\left(\mathrm{M}, \mathrm{S}^{\prime}\right)$
$\mathrm{SP}^{\prime} \mathrm{M} \neq \varnothing$ or $\mathrm{O}(\mathrm{S}, \mathrm{P})$, Bocardo
$\mathrm{A}_{1} \mathrm{O}_{1}=\mathrm{E}\left(\mathrm{M}, \mathrm{P}^{\prime}\right) \mathrm{I}\left(\mathrm{M}, \mathrm{S}^{\prime}\right)$
$\mathrm{S}^{\prime} \mathrm{PM} \neq \varnothing$ or $\mathrm{O}(\mathrm{P}, \mathrm{S})$, No name 
2. VS bound to the subset SP'M:
$\mathrm{EA}_{1}=\mathrm{E}(\mathrm{M}, \mathrm{P}) \mathrm{E}\left(\mathrm{M}, \mathrm{S}^{\prime}\right)$
$\mathrm{M}=\mathrm{SP}$ 'M. If $\mathrm{M} \neq \varnothing$ : $\mathrm{O}(\mathrm{S}, \mathrm{P})$, Felapton/Fesapo
$\mathrm{EO}_{1}=\mathrm{E}(\mathrm{M}, \mathrm{P}) \mathrm{I}\left(\mathrm{M}, \mathrm{S}^{\prime}\right)$
$\mathrm{S}^{\prime} \mathrm{P}^{\prime} \mathrm{M} \neq \varnothing$ or I(S',P'), No name
$\mathrm{IA}_{1}=\mathrm{I}(\mathrm{M}, \mathrm{P}) \mathrm{E}\left(\mathrm{M}, \mathrm{S}^{\prime}\right)$
$\mathrm{SPM} \neq \varnothing$ or I(S,P), Disamis/Dimaris

3. VS bound to the subset $\mathrm{S}^{\prime} \mathrm{P}^{\prime} \mathrm{M}$ :
$\mathrm{EE}=\mathrm{E}(\mathrm{M}, \mathrm{P}) \mathrm{E}(\mathrm{M}, \mathrm{S})$
$\mathrm{M}=\mathrm{S}^{\prime} \mathrm{P} ' \mathrm{M}$. If $\mathrm{M} \neq \varnothing$ : I( $\left(\mathrm{S}^{\prime}, \mathrm{P}^{\prime}\right)$, No name
$\mathrm{IE}=\mathrm{I}(\mathrm{M}, \mathrm{P}) \mathrm{E}(\mathrm{M}, \mathrm{S})$
$\mathrm{S}^{\prime} \mathrm{PM} \neq \varnothing$ or $\mathrm{O}(\mathrm{P}, \mathrm{S})$, No name
$\mathrm{EI}=\mathrm{E}(\mathrm{M}, \mathrm{P}) \mathrm{I}(\mathrm{M}, \mathrm{S})$
$\mathrm{SP}^{\prime} \mathrm{M} \neq \varnothing$ or $\mathrm{O}(\mathrm{S}, \mathrm{P})$, Ferio/Festino/Ferison/Fresison

4. (M' row) VS bound to the subset $\mathrm{S}^{\prime} \mathrm{P}^{\prime} \mathrm{M}^{\prime}$ :
$\mathrm{A}_{2} \mathrm{~A}_{2}=\mathrm{E}\left(\mathrm{M}^{\prime}, \mathrm{P}\right) \mathrm{E}\left(\mathrm{M}^{\prime}, \mathrm{S}\right)$
$M^{\prime}=S^{\prime} P^{\prime} M^{\prime}$. If $M^{\prime} \neq \varnothing: I\left(S^{\prime}, P^{\prime}\right)$, No name
$\mathrm{O}_{2} \mathrm{~A}_{2}=\mathrm{I}\left(\mathrm{M}^{\prime}, \mathrm{P}\right) \mathrm{E}\left(\mathrm{M}^{\prime}, \mathrm{S}\right)$
$\mathrm{S}^{\prime} \mathrm{PM} \mathrm{A}^{\prime} \neq \varnothing$ or $\mathrm{O}(\mathrm{P}, \mathrm{S})$, No name
$\mathrm{A}_{2} \mathrm{O}_{2}=\mathrm{E}\left(\mathrm{M}^{\prime}, \mathrm{P}\right) \mathrm{I}\left(\mathrm{M}^{\prime}, \mathrm{S}\right)$
$\mathrm{SP}^{\prime} \mathrm{M} \neq \emptyset$ or $\mathrm{O}(\mathrm{S}, \mathrm{P})$, Baroco

5. VS bound to the subset S'PM:
$\mathrm{A}_{1} \mathrm{E}=\mathrm{E}\left(\mathrm{M}, \mathrm{P}^{\prime}\right) \mathrm{E}(\mathrm{M}, \mathrm{S})$
$\mathrm{M}=\mathrm{S} P M$. If $\mathrm{M} \neq \varnothing$ : $\mathrm{O}(\mathrm{P}, \mathrm{S})$, No name
$\mathrm{O}_{1} \mathrm{E}=\mathrm{I}\left(\mathrm{M}, \mathrm{P}^{\prime}\right) \mathrm{E}(\mathrm{M}, \mathrm{S})$
$\mathrm{S}^{\prime} \mathrm{P} \mathrm{M} \neq \varnothing$ or I( $\left.\mathrm{S}^{\prime}, \mathrm{P}^{\prime}\right)$, No name
$\mathrm{A}_{1} \mathrm{I}=\mathrm{E}\left(\mathrm{M}, \mathrm{P}^{\prime}\right) \mathrm{I}(\mathrm{M}, \mathrm{S})$
$\mathrm{SPM} \neq \varnothing$ or I(S,P), Darii/Datisi

One sees that the 5 groups of 3 VS each, [which include 7 distinct CVS, (two of them based on ei on M)], are, modulo a relabeling of S,P,M, equivalent.

One may verify the transitivity of the equivalences using the following relabeling maps:

$$
\begin{aligned}
& 1 \leftrightarrow 2: \mathrm{P}^{\prime} \leftrightarrow \mathrm{P} \\
& 1 \leftrightarrow 3: \mathrm{S}^{\prime} \leftrightarrow \mathrm{S}, \mathrm{P}^{\prime} \leftrightarrow \mathrm{P} \\
& 1 \leftrightarrow 4: \mathrm{M} \leftrightarrow \mathrm{M}^{\prime}, \mathrm{S}^{\prime} \leftrightarrow \mathrm{S}, \mathrm{P}^{\prime} \leftrightarrow \mathrm{P} \\
& 1 \leftrightarrow 5: \mathrm{S}^{\prime} \leftrightarrow S \\
& 2 \leftrightarrow 3: \mathrm{S}^{\prime} \mathrm{S}^{\prime} \\
& 2 \leftrightarrow 4: \mathrm{M} \leftrightarrow \mathrm{M}^{\prime}, \mathrm{S}^{\prime} \leftrightarrow \mathrm{S} \\
& 2 \leftrightarrow 5: \mathrm{P}^{\prime} \leftrightarrow \mathrm{P}, \mathrm{S} \leftrightarrow \mathrm{S}^{\prime} \\
& 3 \leftrightarrow 4: \mathrm{M} \leftrightarrow \mathrm{M}^{\prime} \\
& 3 \leftrightarrow 5: \mathrm{P}^{\prime} \\
& 4 \leftrightarrow 5: \mathrm{P}^{\prime}
\end{aligned}
$$

Because there are only 4 subsets per each row, (M or $\left.\mathrm{M}^{\prime}\right)$, when, by relabeling, one maps one "binding subset" into another "binding subset", one also map subsets on which the group of VS, bound to the $1^{\text {st }}$ subset, do not act, act once, or act twice, into subsets on which the $2^{\text {nd }}$ group of VS, bound to the $2^{\text {nd }}$ subset, do not act, act once, or act twice, respectively. This ensures that not only the pairs of premises of the $1^{\text {st }}$ group of VS transform into the pairs of premises of the $2^{\text {nd }}$ group of VS, but the conclusions from the $1^{\text {st }}$ group of VS, transform into the conclusions of the $2^{\text {nd }}$ group of VS.

Another way to show that the 5 groups of $3 \mathrm{VS}$ each are equivalent, is to start with 3 pairs of premises written in the variables $A, B, C$ instead of the usual S,P,M: 
Group 0. All B is A, All B is C

Some B is not A, All B is C

All B is A, Some B is not C

Choosing $\mathrm{B}=\mathrm{M}, \mathrm{A}=\mathrm{P}, \mathrm{C}=\mathrm{S}$ we get the pairs of premises of the $1^{\text {st }}$ group of VS.

Choosing $\mathrm{B}=\mathrm{M}, \mathrm{A}=\mathrm{P}, \mathrm{C}=\mathrm{S}^{\prime}$ we get the pairs of premises of the $2^{\text {nd }}$ group of VS.

Choosing $\mathrm{B}=\mathrm{M}, \mathrm{A}=\mathrm{P}^{\prime}, \mathrm{C}=\mathrm{S}^{\prime}$ we get the pairs of premises of the $3^{\text {rd }}$ group of VS.

Choosing $B=M^{\prime}, A=P^{\prime}, C=S^{\prime}$, we get the pairs of premises of the $4^{\text {th }}$ group of VS.

Finally, choosing $B=M, A=P^{\prime}, C=S$ we get the pairs of premises of the $5^{\text {th }}$ group of VS.

It is as if we represented Group 0, in 5 different system of coordinates: the number of distinct premise pairs, and VS, is at most 3 not 15 . We can further notice that the 5 VS generated by "Some B is not A, All B is C", are equivalent to the 5 VS generated by "All B is A, Some B is not C", via the relabeling A $\leftrightarrow$. This way one can see that the same generic wording of the premises can be represented in different ways, leading to different VS, with different conclusions, but in fact the 5 groups are equivalent: the five VS generated by the pairs of premises $A_{1} A_{1}, E E, A_{1} E, E A_{1}, A_{2} A_{2}$ are equivalent, and the ten $V S$ generated by the pairs of premises $O_{1} A_{1}, I E, O_{1} E, I A_{1}$, $\mathrm{O}_{2} \mathrm{~A}_{2}, \mathrm{~A}_{1} \mathrm{O}_{1}, \mathrm{EI}, \mathrm{A}_{1} \mathrm{I}, \mathrm{EO}_{1}, \mathrm{~A}_{2} \mathrm{O}_{2}$ are equivalent, too.

The above equivalences show again that if a pair of premises entails an LC, it should be admitted as a valid syllogism, VS, even if that conclusion does not have the standard, classical "(S,P) format".

Note that $M$ is not distributed in the $V S A_{2} A_{2}: M^{\prime}=S^{\prime} P^{\prime} M^{\prime} \rightarrow I\left(S^{\prime}, P^{\prime}\right)$, (via ei on $M^{\prime}$ ), and that $A_{2} A_{2}$ turns out to be equivalent to $A_{1} A_{1}: M=S P M \rightarrow I(S, P)$, (via ei on $M$, Darapti). Also, there are pairs of two negative premises in three of the VS - EE, $\mathrm{O}_{1} \mathrm{E}, \mathrm{EO}_{1}$ : EE generates a VS equivalent to Darapti, (or Felapton/Fesapo), and $\mathrm{O}_{1} \mathrm{E}, \mathrm{EO}_{1}$ generate VS equivalent to Darii. Thus there are pairs of premises that entail an LC but do not satisfy the usual "valid syllogisms rules", "the middle term has to be distributed in at least one premise", and, "no valid syllogism has 2 negative premises". One can start with the premises of Darapti and Darii, (i.e., $A_{1} A_{1}$, and resp., $A_{1} I$ ), re-write them using obversion and contraposition as the premises $\mathrm{A}_{2} \mathrm{~A}_{2}$, (resp. $\mathrm{O}_{1} \mathrm{E}$ ), written in other variables, get the conclusions of $\mathrm{A}_{2} \mathrm{~A}_{2}$, (resp. $\mathrm{O}_{1} \mathrm{E}$ ), in those variables, then realize that those conclusions can be re-written, (via appropriate "back relabelings"), as the usual Darapti, $\mathrm{M}=\mathrm{SPM}$, and Darii, $\mathrm{SPM} \neq \varnothing$, conclusions. This way one can use VS which do not satisfy the usual "rules of valid syllogisms" to "bear the burden" of inferring all the conclusions of the CVS from the two VS classes which contain Darapti and resp. Darii.

The "2-row acting" VS:

$\mathrm{EA}_{2}=\mathrm{E}(\mathrm{M}, \mathrm{P}) \mathrm{E}\left(\mathrm{M}^{\prime}, \mathrm{S}\right)$

$\mathrm{S}=\mathrm{SP}$ M, P=S'PM' (SP'M, S'PM'="survive" as the only subsets of S, resp. P, which are not emptied by the premises $\mathrm{EA}_{2}$.) Thus: A(S,SP'M), A(P,S'PM'). One chooses, as independent conclusions $\mathrm{E}(\mathrm{S}, \mathrm{P})\left(=\mathrm{A}\left(\mathrm{S}, \mathrm{P}^{\prime}\right)=\mathrm{A}\left(\mathrm{P}, \mathrm{S}^{\prime}\right)\right)$, (Celarent/Cesare), and, via ei on $\mathrm{P}$ the no name $\mathrm{O}(\mathrm{P}, \mathrm{S})$, and, via ei on S, O(S,P), (Celaront/Cesaro).

$\mathrm{A}_{1} \mathrm{~A}_{2}=\mathrm{E}\left(\mathrm{M}, \mathrm{P}^{\prime}\right) \mathrm{E}\left(\mathrm{M}^{\prime}, \mathrm{S}\right)$

$\mathrm{A}_{2} \mathrm{~A}_{1}=\mathrm{E}\left(\mathrm{M}^{\prime}, \mathrm{P}\right) \mathrm{E}\left(\mathrm{M}, \mathrm{S}^{\prime}\right)$

$\mathrm{S}=\mathrm{SPM}, \mathrm{P}^{\prime}=\mathrm{S}^{\prime} \mathrm{P}^{\prime} \mathrm{M}^{\prime}, \mathrm{A}(\mathrm{S}, \mathrm{P})$ Barbara, I(S,P) Barbari $(\mathrm{S} \neq \varnothing), \mathrm{I}\left(\mathrm{S}^{\prime}, \mathrm{P}^{\prime}\right)$ no name $\left(\mathrm{P}^{\prime} \neq \varnothing\right)$

$\mathrm{P}=\mathrm{SPM}, \mathrm{S}^{\prime}=\mathrm{S}^{\prime} \mathrm{P}^{\prime} \mathrm{M}^{\prime}, \mathrm{A}(\mathrm{P}, \mathrm{S})$ no name, I(S,P) Bramantip $(\mathrm{P} \neq \varnothing), \mathrm{I}\left(\mathrm{S}^{\prime}, \mathrm{P}^{\prime}\right)$ no name $\left(S^{\prime} \neq \varnothing\right)$

$\mathrm{A}_{2} \mathrm{E}=\mathrm{E}\left(\mathrm{M}^{\prime}, \mathrm{P}\right) \mathrm{E}(\mathrm{M}, \mathrm{S}) \quad \mathrm{S}=\mathrm{SP}^{\prime} \mathrm{M}^{\prime}, \mathrm{P}=\mathrm{S}^{\prime} \mathrm{PM}$. Thus: A(S,SP'M'), A(P,S'PM). One chooses, as independent conclusion $\mathrm{E}(\mathrm{S}, \mathrm{P})\left(=\mathrm{A}\left(\mathrm{S}, \mathrm{P}^{\prime}\right)=\mathrm{A}\left(\mathrm{P}, \mathrm{S}^{\prime}\right)\right)$,

(Camestres/Camenes). And, via ei on $\mathrm{P}$, the no name $\mathrm{O}(\mathrm{P}, \mathrm{S})$, plus, 
The $\mathrm{S}, \mathrm{P}, \mathrm{M}, \mathrm{S}^{\prime}, \mathrm{P}^{\prime}, \mathrm{M}^{\prime}$ relabeling transformations showing that $\mathrm{A}_{1} \mathrm{~A}_{2}, \mathrm{~A}_{2} \mathrm{~A}_{1}, \mathrm{~A}_{2} \mathrm{E}, \mathrm{EA}_{2}$ are equivalent, since not only the premises transform into one another, but their respective conclusions, too:

$$
\begin{array}{lll}
\mathrm{A}_{1} \mathrm{~A}_{2} \leftrightarrow \mathrm{A}_{2} \mathrm{~A}_{1}: & \mathrm{M} \leftrightarrow \mathrm{M}^{\prime}, \mathrm{S} \leftrightarrow \mathrm{S}^{\prime}, \mathrm{P} \leftrightarrow \mathrm{P}^{\prime} & \text { or, } \mathrm{S} \leftrightarrow \mathrm{P} \\
\mathrm{A}_{2} \mathrm{E} \leftrightarrow \mathrm{EA}_{2}: & \mathrm{M} \leftrightarrow \mathrm{M}^{\prime} & \text { or, } \mathrm{S} \leftrightarrow \mathrm{P} \\
\mathrm{A}_{1} \mathrm{~A}_{2} \leftrightarrow \mathrm{EA}_{2}: & \mathrm{P} \leftrightarrow \mathrm{P}^{\prime} & \\
\mathrm{A}_{1} \mathrm{~A}_{2} \leftrightarrow \mathrm{A}_{2} \mathrm{E}: & \mathrm{M} \leftrightarrow \mathrm{M}^{\prime}, \mathrm{P} \leftrightarrow \mathrm{P}^{\prime} & \\
\mathrm{A}_{2} \mathrm{~A}_{1} \leftrightarrow \mathrm{A}_{2} \mathrm{E}: & \mathrm{S} \leftrightarrow \mathrm{S}^{\prime} & \\
\mathrm{A}_{2} \mathrm{~A}_{1} \leftrightarrow \mathrm{EA}_{2}: & \mathrm{M} \leftrightarrow \mathrm{M}^{\prime}, \mathrm{S} \leftrightarrow \mathrm{S}^{\prime} &
\end{array}
$$

Note that the eight relabelings are transitive but do not form a group acting on $\mathrm{A}_{2} \mathrm{E}, \mathrm{EA}_{2}, \mathrm{~A}_{1} \mathrm{~A}_{2}, \mathrm{~A}_{2} \mathrm{~A}_{1}$. Nevertheless one can see that each of the four PCP, and their respective LCs, can be recast as any other of the four PCP, and their respective LCs, via some of the above eight relabelings.

Or, one can start with the "generic" pair of premises All B is A, All C is B.

Then, making the obvious choice $\mathrm{B}=\mathrm{M}, \mathrm{A}=\mathrm{P}, \mathrm{C}=\mathrm{S}$, we get $\mathrm{A}_{1} \mathrm{~A}_{2}$, Barbara's premises.

But choosing $\mathrm{B}=\mathrm{M}, \mathrm{A}=\mathrm{P}^{\prime}, \mathrm{C}=\mathrm{S}$, we get the $\mathrm{EA}_{2}$ premises.

And choosing $B=M^{\prime}, A=P^{\prime}, C=S$, we get the $A_{2} E$ premises.

Finally choosing $B=M, A=S, C=P$, we get the $A_{2} A_{1}$ premises.

Thus, no matter what their initial wording is, for any pair of concrete categorical premises presented to us, one can label their 3 terms in such a way, that if the pair entails an $L C$, then it can be expressed as either $A_{1} A_{2}$, or $A_{1} A_{1}$, or $A_{1} I$, (or any other preferred triplet of representatives from each one of the 3 classes of premises that entail LCs). After the LC of $A_{1} A_{2}$, or $A_{1} A_{1}$, or $A_{1} I$, is written down, one can do a "back relabeling" to re-express the conclusion via the most intuitive term labeling suggested by the initial premises.

\section{Conclusions}

Instead of the old accounting rules and restrictions imposed on the classically valid syllogisms - an (S,P) conclusion, the "syllogistic figures", "In any valid syllogism the middle term is distributed at least once", "No valid syllogism has two negative premises", etc., the Venn diagram, (cylindrical or not, but on the usual "3 intersecting circles" Venn diagram, the above facts are difficult to see), approach, allows for simpler rules:

1. The 36 PCP fall into 5 classes: 3 classes entail an LC and 2 do not.

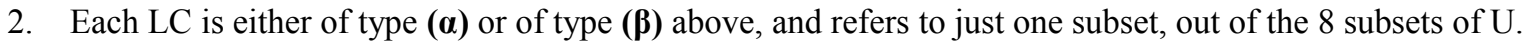

3. Inside each of the 3 classes of PCP entailing an LC, the VS (and CVS) are all equivalent in the sense described above.

4. One may offer two, or even five, "new rules of valid syllogisms". Two negative rules: 1. No two particular premises are allowed (this coincides with one of the old rules). 2. A universal premise and a particular premise, one acting on the middle term $\mathrm{M}$ and the other acting on its complementary set $\mathrm{M}^{\prime}$ are not allowed. (Note that the "old rules of valid syllogisms" were in fact meant to invalidate all but the CVS.) Three positive rules - the rest of the pairs of premises are allowed since they entail LCs: two universal premises acting on the "same row" (either $\mathrm{M}$ or $\mathrm{M}^{\prime}$ ); two universal premises acting on "two rows" (both $\mathrm{M}$ and $\mathrm{M}^{\prime}$ ); a universal premise and a particular premise acting on the same row (either $\mathrm{M}$ or $\left.\mathrm{M}^{\prime}\right)$.

5. As described in Section 4, the logical consequences of the 19 out of 36 possible pairs of premises are as follows: the "(S,P) conclusions" A(S,P), E(S,P), I(S,P), O(S,P) - which are satisfied only by the CVS; $A(P, S)$ entailed only by $A_{2} A_{1} ; I\left(S^{\prime}, P^{\prime}\right)$ and $O(P, S)$. The latter conclusions are entailed by pairs of premises 
which, via ei or not, generate VS which are not CVS (VS ICVS). If one could logically argue that these $\mathrm{I}\left(\mathrm{S}^{\prime}, \mathrm{P}^{\prime}\right), \mathrm{O}(\mathrm{P}, \mathrm{S}), \mathrm{A}(\mathrm{P}, \mathrm{S})$ conclusions are not to be admitted, even if logically entailed by the VS $\backslash \mathrm{CVS}$ pairs of premises, then, indeed, only the CVS are valid. As most of the logic textbooks do, one can restrict the valid syllogisms, by definition, to only the pairs of premises whose entailed consequences are of the "(S,P) type"; or one can use notions like distribution to help eliminate any pair of premises which does not generate a CVS. I do not see a logical motivation for the (S,P) conclusion restriction, neither for the distribution notion.

6. Instead of a Venn diagram one may use a table to list all the PCP entailing a conclusion, together with the LC themselves; please see the table pages at the end.

Because of its lack of symmetry, the usual "3 intersecting circles Venn diagram" model, was used only to "verify" particular syllogisms' validity, but, as far as I know, not to find all the possible logical conclusions from all the categorical pairs of premises. (By inflating the number of cases to consider, the syllogistic figures were a detractor of such an endeavour, too.) See, e.g., Barker (2003). See also, Quine (1982), who proposed as "an hour's pastime" exercise, the Venn diagram checking of all premises' pairs for conclusion entailment.

After this paper was initially written, one had to add the "finding" that the "cylindrical Venn diagram" is in fact a Karnaugh(-Veitch) map for 3 sets. The "cylinder idea" is used to match "close enough" the adjacency displayed by the 8 subsets on the "3-circle Venn diagram". For the same adjacency reason a Karnaugh map for 4 sets is represented as a 4 by 4 square with "glued edges" - which thus becomes a torus. (See Marquand (1881), Veitch (1952), Karnaugh (1953), (Wikipedia.org/wiki/Karnaugh_map.) [“Close enough”, means, e.g., that after Barbara's premises empty 4 subsets out of 8 , the other 4 subsets left would be disconnected on a rectangular diagram, but are still connected on the cylindrical Venn diagram and moreover satisfy $\mathrm{S} \subseteq \mathrm{M} \subseteq \mathrm{P}$.]

\section{References}

Barker, Stephen F. (2003) The Elements of Logic, $6^{\text {th }}$ ed. McGraw-Hill, New York, pp. 28-30, 46-49, 52

Karnaugh, Maurice (1953), The map method for synthesis of combinational logic circuits, Transactions of the American Institute of Electrical Engineers, Part 1, 72, 593-599.

Marquand, Allan (1881), On logical diagrams for $n$ terms, Philosophical Magazine 12, 266-270.

Quine, Willard Van Orman (1982) The Methods of Logic, $4^{\text {th }}$ ed. Harvard University Press, Cambridge, MA, pp. 106-107

Striker, Gisela (Translation, Introduction and Commentary, 2009) Aristotle's Prior Analytics Book I.

Oxford University Press (Clarendon Aristotle Series), Oxford, p. 20

Veitch, Edward, W., A chart method for simplifying truth functions, Proceedings of the Association for Computing Machinery, pp. 127-133, 1952.

Wikipedia.org, https://en.wikipedia.org/wiki/Karnaugh_map 
The class of two universal premises acting on two rows

\begin{tabular}{|c|c|c|c|c|c|c|c|c|}
\hline $\begin{array}{l}\text { PCP (Pair of } \\
\text { Categorical } \\
\text { premises) }\end{array}$ & $\begin{array}{l}\text { Set } \\
\text { translation }\end{array}$ & $\begin{array}{l}\text { Subset } \\
\text { translation }\end{array}$ & Subset LC & Subset ei & CVS LC & CVS ei & VS LC & VS ei \\
\hline \multicolumn{9}{|l|}{$\begin{array}{l}\text { Class of two } \\
\text { universal } \\
\text { premises } \\
\text { acting on two } \\
\text { rows }\end{array}$} \\
\hline \multirow[t]{5}{*}{$\mathrm{A}_{1} \mathrm{~A}_{2}$} & $M P^{\prime}=\varnothing$ & $S P^{\prime} M=\varnothing$ & $S=S P M$ & & $A(S, P)$ & & & \\
\hline & $S M^{\prime}=\varnothing$ & $S^{\prime} P^{\prime} M=\varnothing$ & & $S \neq \varnothing$ & Barbara & $\mathrm{I}(\mathrm{S}, \mathrm{P})$ & & \\
\hline & & $S P M M^{\prime}=\varnothing$ & $P^{\prime}=S^{\prime} P^{\prime} M^{\prime}$ & & & Barbari & $A\left(P^{\prime}, S^{\prime}\right)=$ & \\
\hline & & $S P^{\prime} M^{\prime}=\varnothing$ & & $P^{\prime} \neq \varnothing$ & & & $A(S, P)$ & I(S', $\left.\mathrm{P}^{\prime}\right)$ \\
\hline & & & & & & & (discard) & No name \\
\hline \multirow{6}{*}{$\mathrm{A}_{2} \mathrm{~A}_{1}$} & & & & & & & & \\
\hline & $P M^{\prime}=\varnothing$ & SPM'= & $P=S P M$ & & & & $A(P, S)$ & \\
\hline & $M S^{\prime}=\varnothing$ & $S^{\prime} P M^{\prime}=\varnothing$ & & $P \neq \varnothing$ & & $\mathrm{I}(\mathrm{S}, \mathrm{P})$ & No name & \\
\hline & & $S^{\prime} P M=\varnothing$ & $S^{\prime}=S^{\prime} P^{\prime} M^{\prime}$ & & & Bramantip & $A\left(S^{\prime}, P^{\prime}\right)=$ & \\
\hline & & $S^{\prime} P ' M=\varnothing$ & & $S^{\prime} \neq \varnothing$ & & & $A(P, S)$ & I(S',P') \\
\hline & & & & & & & (discard) & No name \\
\hline \multirow{5}{*}{$\mathrm{EA}_{2}$} & ג- & & & & & & & \\
\hline & $\begin{array}{l}\mathrm{M} \mathrm{I}^{\prime}=\varnothing \\
\mathrm{SM}=\varnothing\end{array}$ & S'PM $=\varnothing$ & $S=S P^{\prime} \mid \mathrm{IV}$ & $S \neq \varnothing$ & Celarent/ & $\mathrm{O}(\mathrm{S}, \mathrm{P})$ & & \\
\hline & & $S^{\prime} M^{\prime}=\varnothing$ & $\mathrm{P}=\mathrm{S}^{\prime} \mathrm{PM}$ & & Cesare & Celaront/ & $E(S, P)$ & \\
\hline & & $S P^{\prime} M^{\prime}=\varnothing$ & & $P \neq \varnothing$ & & Cesaro & (discard) & $O(P, S)$ \\
\hline & & & & & & & & No name \\
\hline \multirow[t]{5}{*}{$\mathrm{A}_{2} \mathrm{E}$} & $P M^{\prime}=\varnothing$ & $S P M '=\varnothing$ & $S=S P^{\prime} M^{\prime}$ & & $E(S, P)$ & & & \\
\hline & $M S=\varnothing$ & $S^{\prime} P M^{\prime}=\varnothing$ & & $S \neq \varnothing$ & Camestres/ & $\mathrm{O}(\mathrm{S}, \mathrm{P})$ & & \\
\hline & & $S P M=\varnothing$ & $P=S^{\prime} P M$ & & Camenes & Camestrop & $/ E(S, P)$ & \\
\hline & & $S P^{\prime} M=\varnothing$ & & $P \neq \varnothing$ & & Camenop & (discard) & $O(P, S)$ \\
\hline & & & & & & & & No name \\
\hline & & & & & & & & \\
\hline \multicolumn{4}{|c|}{ Total \# of PCP $=4$, Total \# of VS in this class $=12$} & & 3 & 4 & 1 & 4 \\
\hline & & & & & 3 CVS & 4 ei CVS & 1 VSICVS & $\begin{array}{l}4 \text { ei } \\
\text { VSICVS }\end{array}$ \\
\hline
\end{tabular}


5 Groups of 3 pairs, each set of 3 pairs being bound on adjacent subsets.

\section{Group 1}

$\mathrm{A}_{1} \mathrm{~A}_{1}$

$M^{\prime}=\varnothing \quad S P^{\prime} M=\varnothing \quad M=S P M$

$M S^{\prime}=\varnothing \quad S^{\prime} P^{\prime} M=\varnothing$

$S^{\prime} P M=\varnothing$

$S^{\prime} P^{\prime} M=\varnothing$

$\mathrm{O}_{1} \mathrm{~A}_{1} \quad \mathrm{MP}^{\prime} \neq \varnothing \quad \mathrm{S}^{\prime} \mathrm{P} M=\varnothing \quad \mathrm{SP}^{\prime} \mathrm{M} \neq \varnothing$

$\mathrm{MS}^{\prime}=\varnothing \quad \mathrm{S}^{\prime} \mathrm{P}^{\prime} \mathrm{M}=\varnothing$

$S P^{\prime} M \neq \varnothing$

$S^{\prime} P^{\prime} M \neq \varnothing$

(discard)

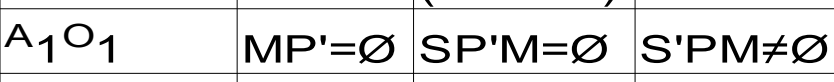

$M S^{\prime} \neq \varnothing \quad S^{\prime} P^{\prime} M=\varnothing$

$S^{\prime} P M \neq \varnothing$

$S^{\prime} P^{\prime} M \neq \varnothing$

(discard)

Total VS $=3$

Group 2

$\mathrm{EA}_{1}$

$\mathrm{MP}=\varnothing$

$M S^{\prime}=\varnothing \quad S^{\prime} P M=\varnothing$

$S^{\prime} P M=\varnothing$

$\mathrm{S}^{\prime} \mathrm{P} \cdot \mathrm{M}=\varnothing$

$\mathrm{EO}$

Total $\mathrm{VS}=3$

Group 3

EE

\begin{tabular}{l|l}
$\mathrm{IA}_{1}$ & $\mathrm{MP} \neq \varnothing$ \\
\hline & $\mathrm{MS}^{\prime}=\varnothing$
\end{tabular}

El

Total VS $=3$

$S P M=\varnothing \quad S^{\prime} P^{\prime} M \neq \varnothing$

$S P^{\prime} M=\varnothing$

$S^{\prime} P M \neq \varnothing$

SPM $\neq \varnothing$

(discard)

$S^{\prime} P M=\varnothing \quad S P M \neq \varnothing$

$S^{\prime} P ' M=\varnothing$

$S P M \neq \varnothing$

S'PM $\neq \varnothing$

(discard)

(discard)

IE

$\mathrm{MP}=\varnothing$

$S P M=\varnothing$

$\mathrm{MS}=\varnothing \quad \mathrm{S}^{\prime} \mathrm{PM}=\varnothing$

$S P M=\varnothing$

$S P^{\prime} M=\varnothing$

$\mathrm{MP} \neq \varnothing \quad \mathrm{SPM}=\varnothing \quad \mathrm{S}^{\prime} \mathrm{PM} \neq \varnothing$

$\mathrm{MS}=\varnothing$

$S P^{\prime} M=\varnothing$

$S^{\prime} P M \neq \varnothing$

SPM $\neq \varnothing$

(discard)

$\mathrm{MP}=\varnothing \quad \mathrm{SPM}=\varnothing \quad \mathrm{SP} \mathrm{M} \neq \varnothing$

$\mathrm{MS} \neq \varnothing$

$S^{\prime} P M=\varnothing$

$S P^{\prime} \mathrm{M} \neq \varnothing$

SPM $\neq \varnothing$

(discard)
CVS LC

CVS ei

VS LC

I(S,P)

Darapti

$\mathrm{O}(\mathrm{S}, \mathrm{P})$

Bocardo

\section{$M \neq \varnothing$}

$M=S^{\prime} P^{\prime} M$

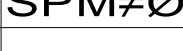

Dimaris

Disamis/
$\mathrm{O}(\mathrm{S}, \mathrm{P})$

Felapton/

Fesapo
1

$\mathrm{I}(\mathrm{S}, \mathrm{P})$
$O(P, S)$

No name

1

1

$\mathrm{I}\left(\mathrm{S}^{\prime}, \mathrm{P}^{\prime}\right)$

No name

$M \neq \varnothing$

1

1

1

$\mathrm{O}(\mathrm{P}, \mathrm{S})$

No name

$\mathrm{O}(\mathrm{S}, \mathrm{P})$

Ferio/

Festino/

Ferison/

Fresison
I( $\left(S^{\prime}, P^{\prime}\right)$

No name 


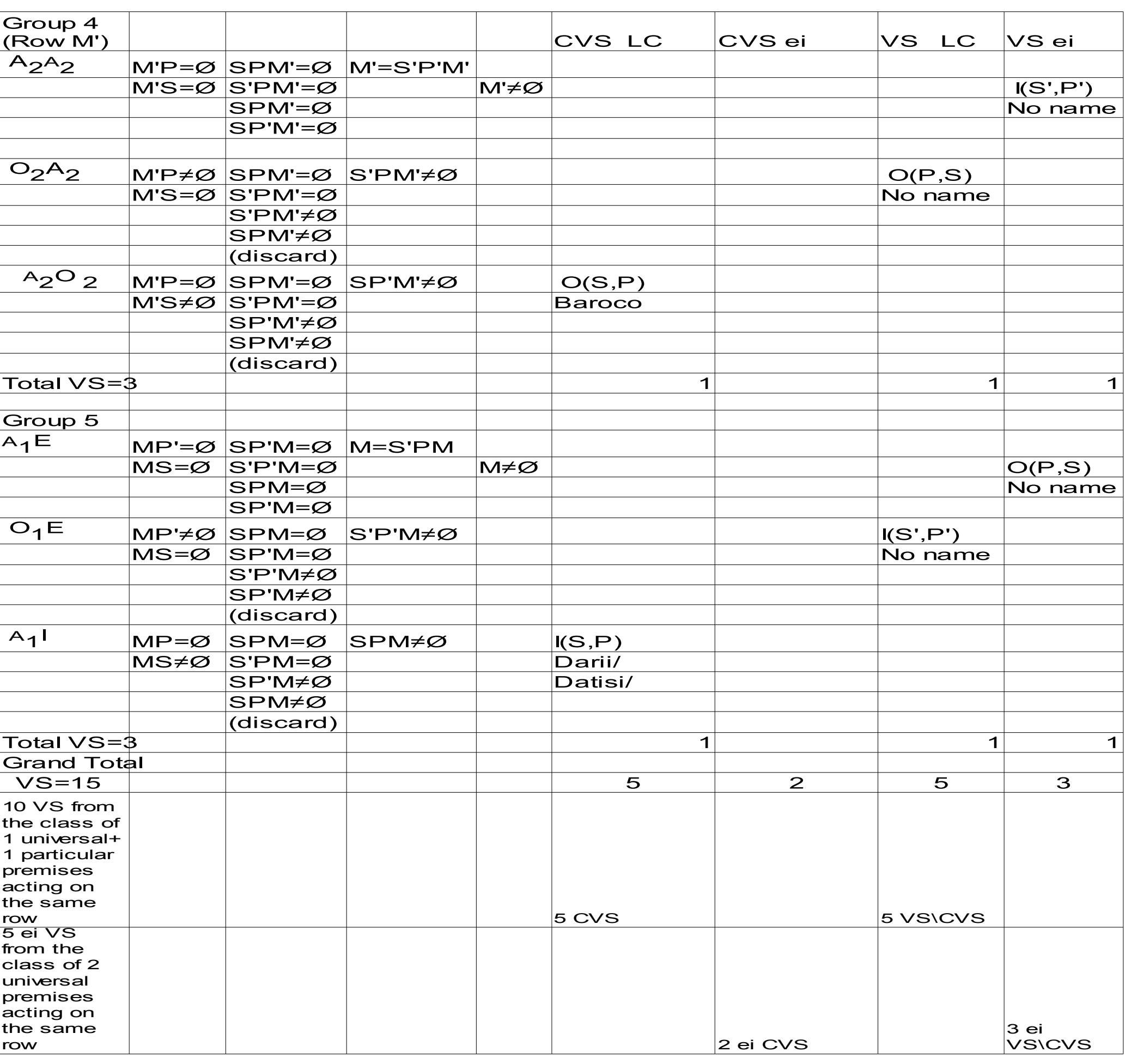

